\title{
Research on Laterally Restrained Built Up Steel Beam Under Dynamic Response
}

\author{
Sangeetha K, Vimala S
}

\begin{abstract}
This paper presents the analytical investigation of laterally restrained built up steel beam under dynamic response using finite element software ABAQUS. The main objective of this study was to estimate the mode shapes and mode shape curvature of the laterally restrained built up steel beam. The three parameters such as modal frequencies, mode shapes and mode shape curvature are suggested for identifying the damages in built up steel beam. Damage assessment is done by linear perturbation free vibration study using finite element software ABAQUS. The frequency extraction methods for built up steel beam was done in ABAQUS to get the dynamic response. The Lanczos eigen solver was used for finding the mode shapes. Eigen value extraction, the natural frequencies and the corresponding mode shapes of a system were studied.
\end{abstract}

Keywords- Dynamic response, frequency, mode shape, curvature mode shape.

\section{INTRODUCTION}

Structural steel is used in load bearing frames in buildings , and as members in trusses, bridges, and space frames. It requires a fire resistance and corrosion protection. The main advantage of structural steel are strength, speed of erection, prefabrication and demountability. Damage accumulated in the structures due to its environmental loadings such as wind, snow, and ice. Structural Health Monitoring refers to the process of implementing damage detection and characterization strategy for engineering structures. Here damage is defined as the changes to the material and geometric properties of a structural systems, including changes to boundary conditions and system connectivity, which adversely affect the system performance. The process of implementing damage detection and characterization strategy for engineering structures is known as structural health monitoring. Here damage is defined as the changes to the material and geometric properties of a structural systems, including changes to boundary conditions and system connectivity, which adversely affect the system performance. Here, the dynamic response of the steel beam are identified by using finite element software ABAQUS. The lanczos eigen solver is used for finding mode shapes and frequencies by using eigen value extraction. Two damage identification approaches using structural information and global models by (N.Hu et al., 2001) have been developed for detecting damage location by numerical and experimental investigation. (C.Zang et al.,2007) reduced frequency domain correlation criteria by means of

Revised Manuscript Received on April 12, 2019.

Sangeetha K, PG student, Department of Civil Engineering, PSNA College of Engineering and Technology, Dindigul, Tamil Nadu, India.

Vimala S, Professor, Department of Civil Engineering, PSNA College of Engineering and Technology, Dindigul, Tamil Nadu, India. window averaging. Damaged indicators are calculated from a set of window averaged integration of GSC and GAC functions over the measurement of frequency range to establish the performance of correlation measures using damage identification. (Ahmed A.Elshafey et al.,2011) conducted an experimental study using hinged-fixed beam to illustrate to use and the feasibility of the technique is used for identifying the location of the damage and the Frequency Response Function is used to identify the existence of damage and location of damage. (Miroslav Pastor et al., 2012) they compared the quantitative correlation between the dynamic response of the modal test data. (V.Srinivas et al., 2013) Damage identification studies are carried out based on the dynamic properties of the structures such as frequencies and mode shapes using advanced techniques ANN and GA. And also by using combined objective function of frequencies and mode shapes, GA is used to locate and quantify the damages. (Resmi G et al.,) presents multi criteria damage approach is based on modal parameters extracted from the free vibration responses for laterally restrained steel beam. Finite Element Method ABAQUS to quantify local damages using extracted mode shapes and curvature mode shapes, damage quantification using MAC and CAC is found to predict the intensity of damages in the structures to detect the damages. (Richard Frans et al.,2017) focuses on the identification and location of the damage of structures using two techniques, i.e., mode shapes and damage locating vector methods. Both the methods are applied to shear building and plane truss structures.

\subsection{Built up steel beam}

Built up steel beam is known as compound beam. A beam is made of structural units which are riveted, bolted, or welded together. When the span, load and corresponding to the bending moment are of such magnitudes that rolled steel beam section becomes inadequate to an provide required section modulus. The types of steel section are Isection, T-section, C- section and Angle section. Here, built up channel section has been used and it is generated by using finite element software - ABAQUS.

\subsection{Laterally restrained steel beam}

Laterally restrained steel beam consists of top flange of the beam is restrained against lateral buckling in the plane of compression flange. In the absence of lateral restraint, due to 
compressive stress, the flange tends to buckle. And, at the same time, the tension flange tries to remain straight. This results in lateral torsional buckling. The capacity of the section in resisting bending thus reduces. To avoid this, full lateral support of the beam is essential. In many steel structures, especially in buildings, beams carry floor decks on top of them, and these floor decks provide restraint to the compression flange. In the absence of any such restraints, and in case the lateral buckling of beams is not accounted for in design, the designer has to provide adequate lateral supports to the compression flange.

\subsection{Dynamic response}

Dynamic response is response of the structure to dynamic load. Dynamic loads induce acceleration and the resisting forces and whereas the static loads induce only resisting forces. The dynamic response of the system gives an idea, that how the system will behave under the particular type of dynamic force. This is very essential in designing to resist the earthquake vibrations. The vibration will respond to dynamic force of particular frequency. This response are investigated at the different strain rates. It also subjected to cyclic loading. Here, to find the Mode shapes, Curvature mode shape, Modal assurance criteria and Curvature assurance of the built up steel beam.

\section{PROCESSING OF DAMAGE ASSESSMENT PROCESS}

i. Model both baseline and damaged laterally restrained beams in FE software ABAQUS.

ii. Conduct a linear perturbation free vibration analysis in ABAQUS for built up steel beam to get the dynamic response.

iii. Extract modal parameters such as frequency and mode shape using Lanczos eigen solver of ABAQUS.

iv. Export the mode shape thus obtained to MS Excel to calculate the mode shape curvature.

v. Identify the intensity of change in structural response using Modal Assurance Criteria (MAC) and Curvature Assurance Criteria (CAC).

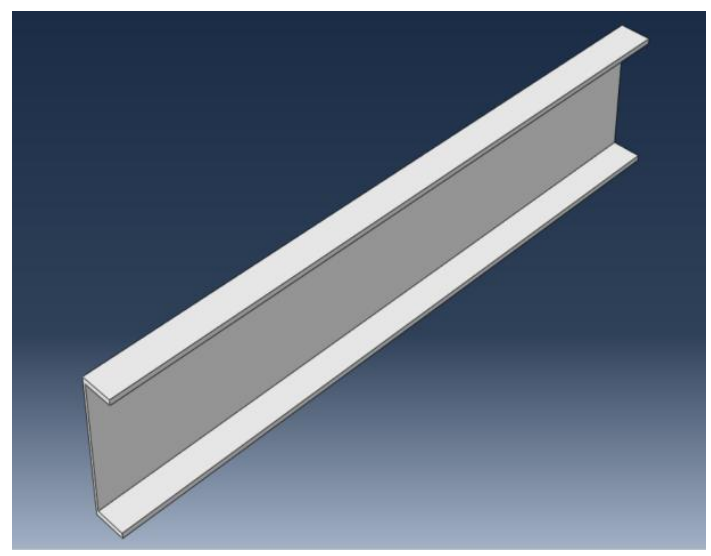

Fig 1. Channel section

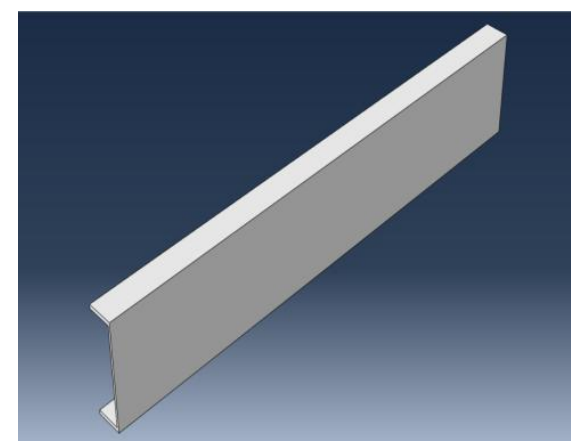

Fig 2. Inverted channel section

\subsection{Vibration analysis using ABAQUS}

The frequency extraction procedure in ABAQUS is a linear perturbation procedure which performs eigen value extraction to calculate the natural frequencies and the corresponding mode shapes of a system. The Eigen value problem for the natural frequencies of an undamped finite element model is given by

$$
\left(-\omega^{2} M^{\mathrm{MN}}+K^{\mathrm{MN}}\right) \Phi^{\mathrm{N}}=\mathbf{0}
$$

where,

$\mathrm{M}^{\mathrm{MN}}$ is the mass matrix

$\mathrm{K}^{\mathrm{MN}}$ is the stiffness matrix

$\boldsymbol{\Phi}^{\mathrm{N}}$ is the eigenvector (the mode of vibration)

$\omega$ is the natural frequency (the mode of vibration)

$\mathrm{M}$ and $\mathrm{N}$ are degrees of freedom Abaqus/Standard.

The Lanczos solver is the traditional architecture with the default eigenvalue extraction method because it has the most general capabilities. For the Lanczos method, the maximum frequency of interest or the number of eigenvalues has to be provided. Loads are ignored during frequency extraction analysis. The density of the material must be defined. Predefined fields cannot be prescribed during natural frequency extraction. Output variables such as stress, strain, and displacement which represent mode shapes are also available for each eigenvalue, these quantities are perturbation values and represent mode shapes.

\subsection{Mode shape curvature}

Mode shape curvature, which is the double derivative of mode shape, is obtained by the following,

$$
M C, \Phi{ }_{n, m}^{\prime \prime}=\left(\frac{\Phi_{n+1, m} 2 \Phi_{n, m} \Phi_{n-1, m}}{d^{2}}\right)
$$

where,

$\mathrm{n}=$ Number of node,

$\mathrm{m}=$ Number of mode,

$\mathrm{d}=$ Distance between two nodes,

$\Phi=$ Displacement mode shape.

\subsection{Modal Assurance Criteria and Curvature Assurance Criteria}

Modal Assurance Criteria (MAC) and Curvature Assurance Criteria (CAC) are the correlation indicators used to quantify the changes in dynamic response such as mode shape and curvature mode shape respectively of the built up steel beam. These are used to quantify the changes in structural response of the beam.

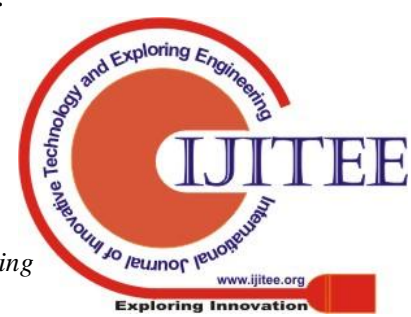




\section{VERIFICATION OF ABAQUS MODEL}

The ABAQUS model is verified by using the classical solution of free vibration of continuous system. The Euler Bernoulli's beam theory is one of the basic assumptions used in the differential equation of continuous system. The standard result of continuous system are derived for the beam. The fundamental frequency of a beam is obtained as

$$
f=\frac{\Pi}{2 L^{2}} \sqrt{\frac{E I}{A \rho}}
$$

where,

f-fundamental frequency,

L-Length of beam,

E-Young's Modulus of material,

I-Moment of Inertia,

A-Area of cross section and

$\rho$-Density of material.

ISMC 350 section is considered with $2 \mathrm{~m}$ length of beam,

$\mathrm{E}=210 \times 10^{9} \mathrm{~N} / \mathrm{m}^{2}$,

$\mathrm{I}=10008 \times 10^{4} \mathrm{~mm}^{4}$

$\mathrm{A}=5366 \times 10^{4} \mathrm{~m}^{2}$. From equation, the fundamental frequency is obtained as $277.385 \mathrm{~Hz}$.

\section{ILLUSTRATIONS \& RESULTS}

The damage is illustrated using a Finite Element modelling of built-up steel beam beam are done using ABAQUS 6.11. The built-up channel section is taken as ISMC 350, which is a standard built up section with $2 \mathrm{~m}$ span, pinned-pinned end conditions, whose section properties are shown in Table 2. The material properties assigned are given in Table 3.

\section{Table 2 Section properties of ISMC 350}

\begin{tabular}{|l|l|}
\hline Thickness of flange & $13.5 \mathrm{~mm}$ \\
\hline Thickness of web & $8.1 \mathrm{~mm}$ \\
\hline Depth of C-section & $350 \mathrm{~mm}$ \\
\hline Width of flange & $100 \mathrm{~mm}$ \\
\hline
\end{tabular}

Table 3 Material properties of beam

\begin{tabular}{|l|l|}
\hline Poisons ratio & 0.3 \\
\hline Modulus of elasticity & $210 \times 10^{9} \mathrm{~N} / \mathrm{m}^{2}$ \\
\hline Density & $7850 \mathrm{~kg} / \mathrm{m}^{3}$ \\
\hline
\end{tabular}

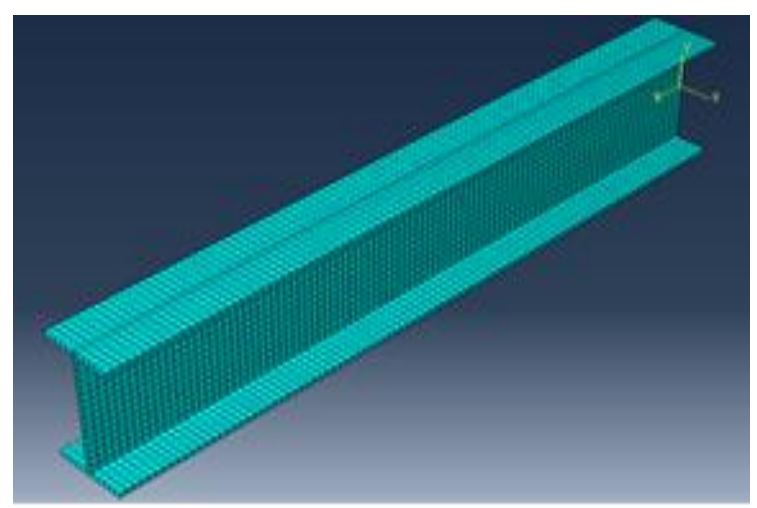

Fig.2 Finite element mesh of steel beam

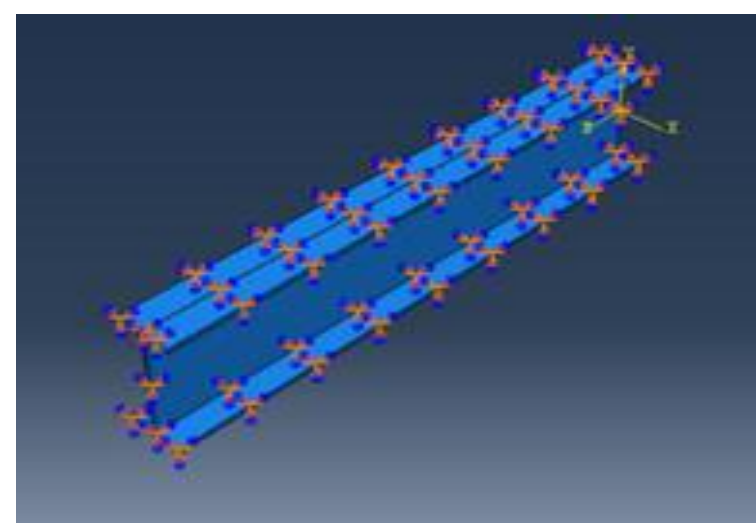

Fig.3 Boundary condition of laterally restrained built up channel section beam

\section{RESULTS AND DISCUSSIONS}

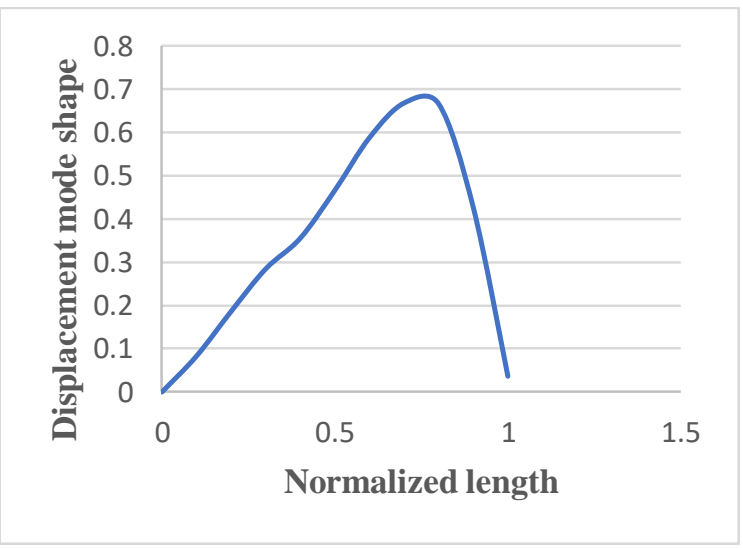

Fig.4 Mode Shape For AA

It is clear from fig. 5(a), 5(b) and 5(c) that the curvature mode shapes obtained from equation shows a sudden variation at the location of damage when compared to baseline undamaged one. The intensity of location of localised cross section are $0.25 \mathrm{~L}, 0.5 \mathrm{~L}$ and $0.75 \mathrm{~L}$ are termed as varying localised cross section case1, case 2 and case 3 respectively.

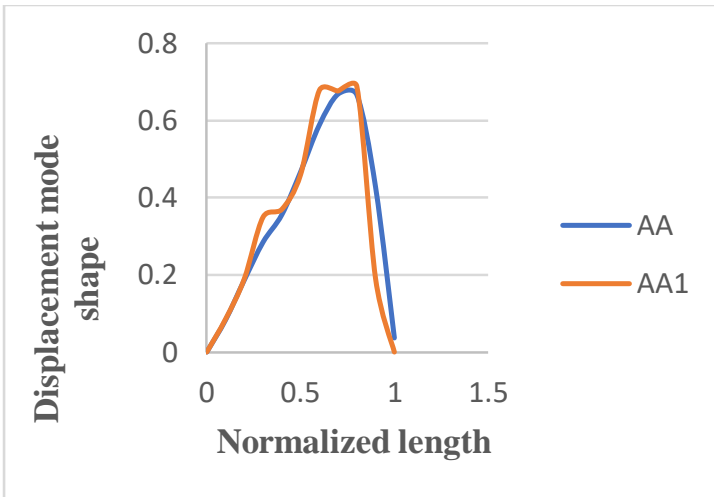

Fig.5(a) Mode Shape For AA and AA1 


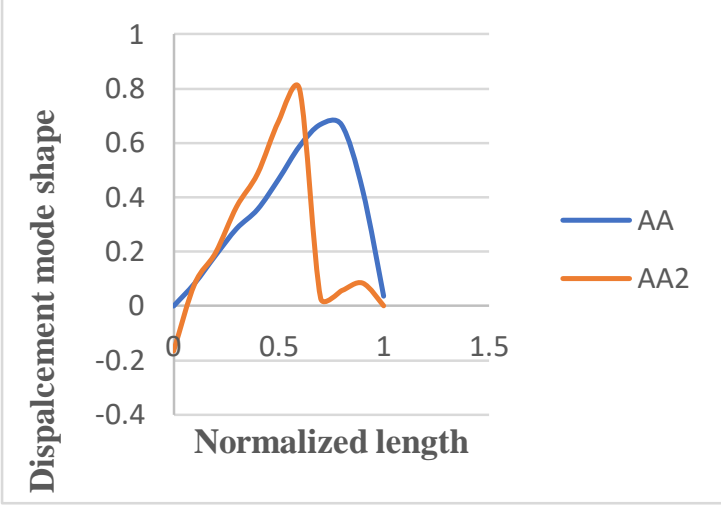

Fig.5(b) Mode Shape For AA and AA2

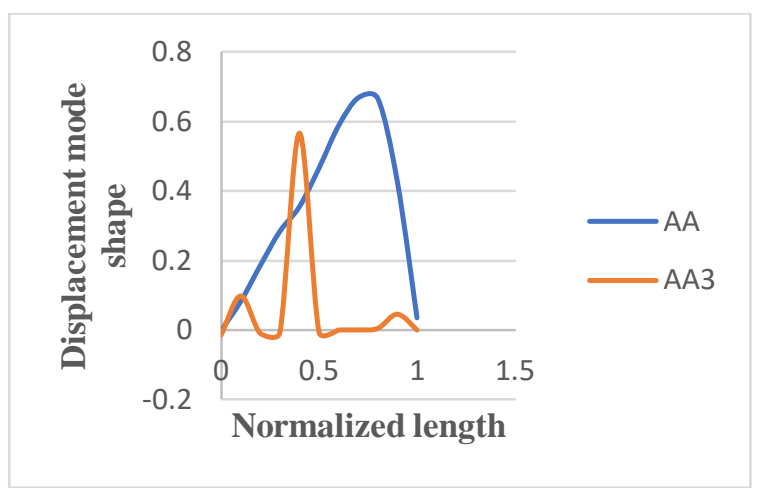

Fig.5(c) Mode Shape For AA and AA3

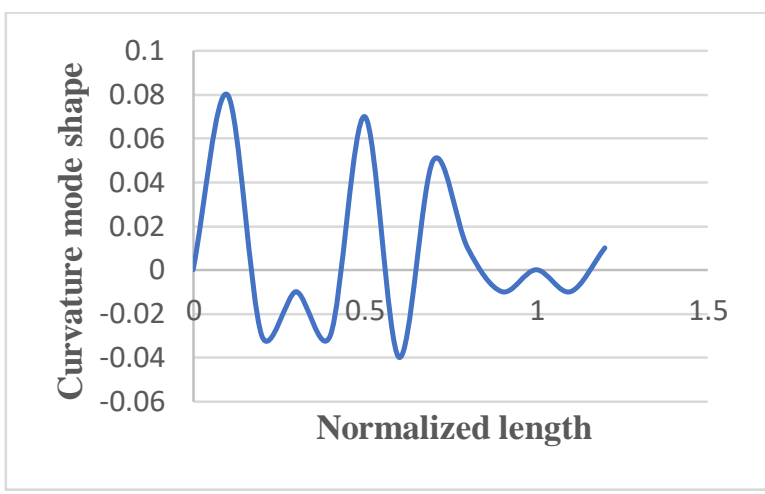

Fig.6 Curvature Mode Shape For AA

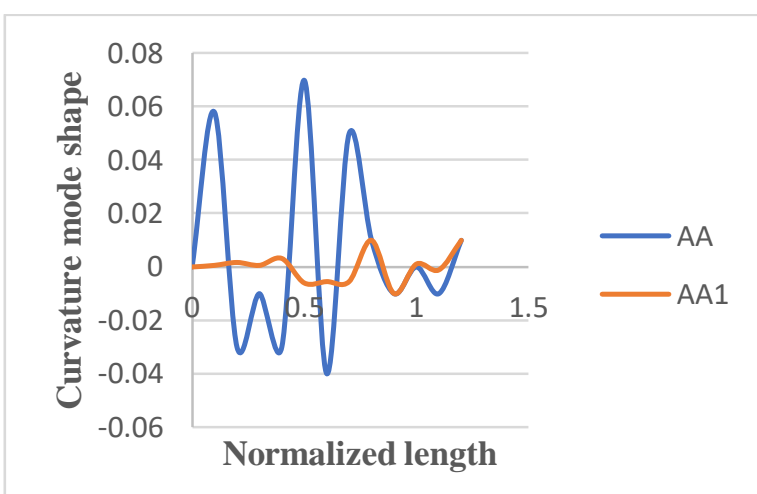

Fig.7(a)Curvature Mode Shape For AA and AA1

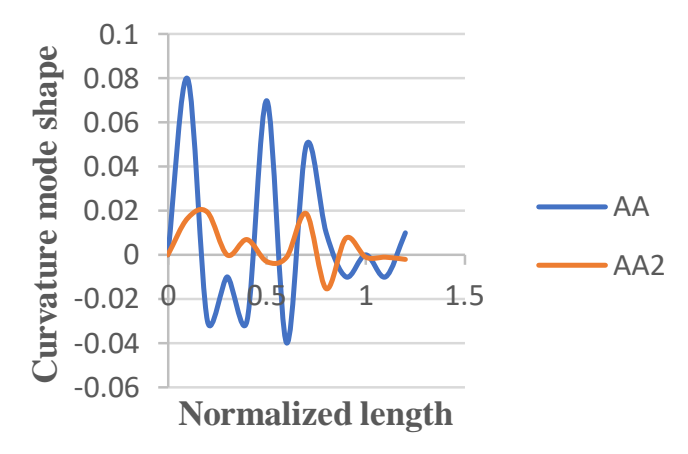

Fig.7(b) Curvature Mode Shape For AA and AA2

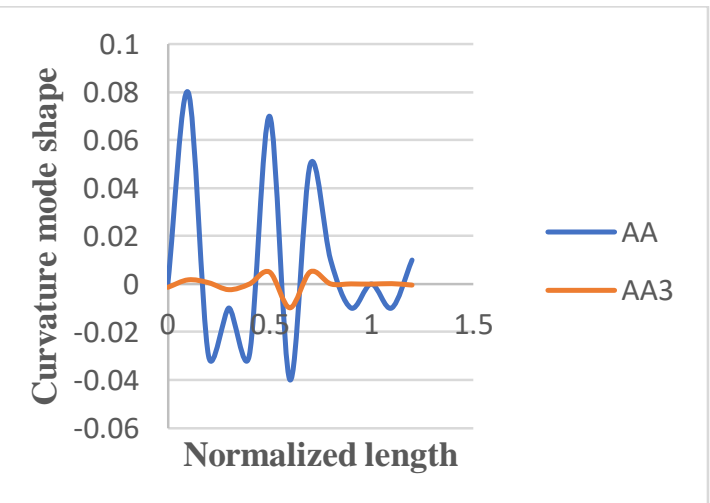

Fig.7(c) Curvature Mode Shape For AA and AA3

Thus, the mode shape and curvature mode shape can be used to identify the damage and locate the damage in laterally restrained built-up channel section beams. MAC and CAC are calculated using equations (3) and (4) for all cases of damages to quantify the change in the dynamic response such as mode shape and curvature mode shape are shown in fig 8(a), 8(b) and 8(c).

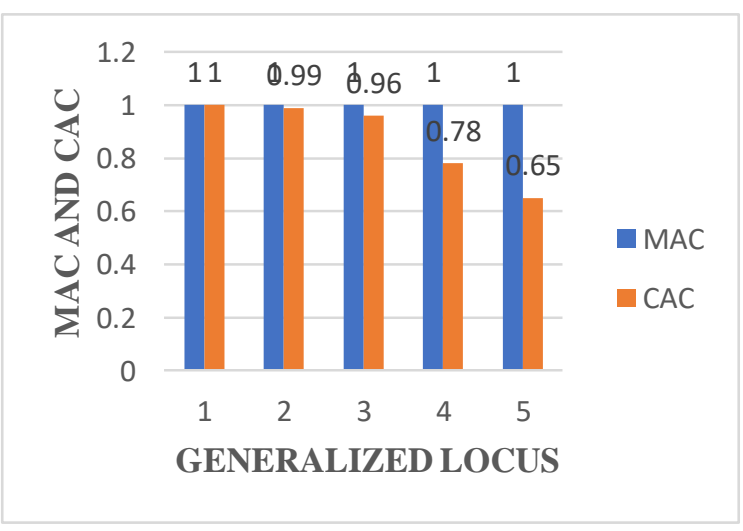

Fig.8(a) MAC and CAC For AA1 


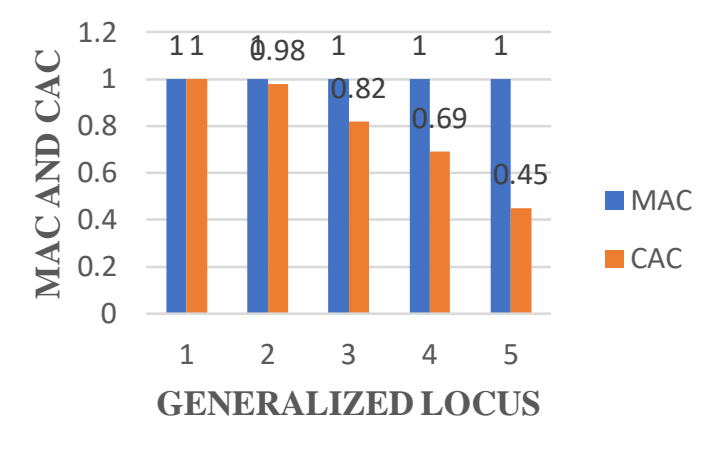

Fig.8(b) MAC and CAC For AA2

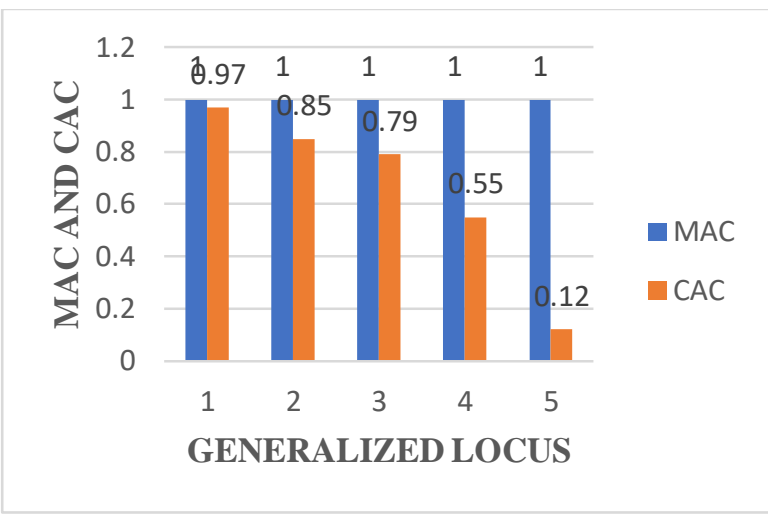

Fig.8(c) MAC and CAC For AA3

From the figures, it shows that the damaged induced is localised one. The MAC is found to be 1 for all causes of damages are described in this paper. The CAC values are varying with the respect to the cross section and location of damage in the beam. Here, the MAC and CAC are quantifying the changes in mode shape and curvature mode shape graphs with respect to corresponding baseline in terms of 0 and 1 . Here, MAC values is near to and the CAC values is near to zero which indicate the presence of damage in the structure.

Hence, the MAC and CAC will quantify the damages and the intensities of damages in the built-up steel beam.

\section{CONCLUSION}

In this paper, the damage identification is based on modal parameters which were extracted from linear perturbation free vibration response for laterally restrained built-up steel beam. This method is used to develop an accurate beam using ABAQUS, and to quantify the damage using the extracted mode shapes and curvature mode shapes. The important conclusions of the steel beam are as follows, Damage quantification using MAC and CAC is found to predict the intensity of damage in the structure. MAC is a global damage quantifying parameter which entirely depends on mode shape, while CAC is a local damage quantifying parameter which entirely depends on curvature mode shape graphs. CAC can be used as a tool for quantifying the change in curvature mode shape graph due to all localised cross sectional damages. The proposed method is able to identify damage in laterally restrained built up steel beam under dynamic response.

\section{REFERENCES}

1. Ahmed A.Elshafey, H.Marzouk and M.R.Haddara(2011), 'Experimental Damage Identification Using Modified Mode Shape Diffrence',Journal of Marine Science and Applications, Vol-10, pp150-155

2. Byoeng Hwa Kim, Norris Stubbs, Taehyo Park(2005), 'A new method to extract modal parameters using output-only responses', Journal of Sound and Vibration, Vol-282, pp.215230

3. A.H. Gandomi, M.G. Sahab, A. Rahaei and M. Safari Gorji(2008), 'Development in Mode Shape-Based Structural Fault Identification Technique', World Applied Sciences Journal, Vol-5 (1), pp. 29-38.

4. Hanady El-Dehemy(2017), 'Static and Dynamic Analysis Web Opening of Steel Beams', World Journal of Engineering and Technology, Vol-5, pp. 275-285

5. N.Hu, X.Wang, H.Fukunaga, Z.H.Yao, H.X.Zhang, Z.S.Wu(2001), 'Damage assessment of structures using modal test data', International Journal of Solids and Structures, Vol38, pp.3111-3126.

6. Z. Ismail, H.Abdul Razak, A.G. Abdul Rahman(2006), 'Determination of damage location in RC beams using mode shapes deriviatives',Engineering Strctures, Vol-28, pp.15661573.

7. Miroslav Pastor, Michal Binda, Tomas Harcarik(2012), 'Modal Assurance Criterion', Vol-48, pp.543-548.

8. E.Parloo, P.Guillaume and M. Van Overmeire(2003), 'Damage assessment using mode shape sensitivities',Mechanical system and signal processing, Vol17(3), pp.499-518.

9. Resmi.G and Baskar.K(2012), 'Damage Assessment of Laterally Restrained Steel Beams using Dynamic Response', CARE Journal of Applied Research,(ISSN 2321-4090), pp.30-36.

10. Rihard Frans, Yoyong Arfiadi, Herman Parung(2017), 'Comparative study of mode shapes curvature and damage locating vector methods for damage detection of structures', Procedia Engineering, Vol-171, pp.1263-1271.

11. V.Srinivas, C.Antony Jeyasehar, K. Ramanjaneyulu(2013), 'Computational Methodologies for Vibration-Based Assessment of Structures, Vol-13, pp.1-26.

12. C.Zang, M.I.Friswell, M.Imergun(2007), 'Structural Health Monitoring and Damage Assessment Using Frequency Response Correlation Criteria', Journal of Engineering Mechanics, Vol-133, pp.981-993. 